\title{
Investigating the Effectiveness of Input Enhancement in Relation to L2 Vocabulary Learning
}

\author{
Farzan Homayounmehr, Seyyed Fariborz Pishdadi Motlagh* \\ Department of Foreign Languages and Literature, University of Tabriz, Tabriz, Iran
}

Email address:

Fpishdadi@Yahoo.com (S. F. Pishdadi Motlagh), Farzan_3210@yahoo.com (F. Homayounmehr)

\section{To cite this article:}

Farzan Homayounmehr, Seyyed Fariborz Pishdadi Motlagh. Investigating the Effectiveness of Input Enhancement in Relation to L2 Vocabulary Learning. International Journal of Language and Linguistics. Special Issue: Applied Linguistics and English Language Teaching Methodologies in All Fields. Vol. 4, No. 2-1, 2015, pp. 1-8. doi: 10.11648/j.ijll.s.2016040201.11

\begin{abstract}
The purpose of this study was to investigate how differently input enhancement devices of bolding, underlining, and capitalizing affect L2 learners' vocabulary learning. For this purpose, the study adopted a quasi-experimental design with a proficiency test to find the homogeneity of groups. Three classes were selected as the experimental groups $(n=60)$, and each class was conducted by one of the input enhancement main categories. Subjects attended in six sessions to make them familiar with advantages of input enhancement in relation to vocabulary learning. Each group received different strategies and then, the researcher taught and employed those inputs in texts along with target words. Learners' progress was measured during the six sessions of employing those inputs in responding to vocabulary questions. One-way ANOVAs series with LSD or post hoc comparisons showed that all three inputs were effective in responding to target vocabulary words but the bolding group did better than the other groups and, finally bolding target words were more effective in fostering L2 learners' vocabulary learning. These outcomes propose that using input enhancement to answer target words are the most useful factors but bolding in this study outperformed the other ones in developing learners' awareness to answer vocabulary tests. It can also be concluded that capitalizing is the least effective input compared to underlining and bolding input in terms of their efficacy.
\end{abstract}

Keywords: Vocabulary, Focus on Form and Implicit Fonf

\section{Introduction}

The Field of Second Language Acquisition (SLA) is witnessing an increasing interest in the idea that drawing learners' attention to the formal features of second language (L2) input is beneficial, and in some cases necessary for optimal L2 development (Schmit, 1993). Focus on Form refers to a particular type of form focused instruction, i.e., the treatment of linguistic form in the context. Whereas learners are able to acquire linguistic forms without any instructional intervention, they typically do not achieve very high levels of linguistic competence from entirely meaning-centered instruction. Doughty and Williams (1998) pointed out that focus-on-form interpretations range from a very narrow and implicit view adopted by Long (1991) to a broader, liberal and more explicit view as presented in the work of Dekeyser (1998).

Manipulation input often takes the form of visual/textual input enhancement, in which the target forms become visually salient. The idea behind input enhancement is that by making formal aspects of input more salient learners will be more likely to notice targeted forms, resulting in more intake, the subset of the input data that becomes available for further language processing. Sharwood Smith (1991) contends that the most obvious way to try to affect subconscious processing beneficially is by making relevant target forms in the input salient. He further argues that making the input salient (input enhancement) has a highly positive effect on the rate and accuracy of L2 acquisition.

There is an agreement among vocabulary specialists that lexical knowledge is the heart of language learning (Coady, 1997; Coady\&Huckin, 1997). Since vocabulary is considered as the heart of language learning, researchers are busy trying to provide more effective ways of teaching L2 vocabulary to second language (L2) teachers and educators. Learners also would like to know the ways to learn second language target vocabulary in a fast and easy way.

Research Question:

Do Bolding, Capitalizing, Underlining target words have different effects on L2 learners' vocabulary knowledge 
enhancement?

\section{Review of the Related Literature}

\subsection{Vocabulary Knowledge}

Vocabulary learning is defined as the storage of the phonological, morpho- syntactic and semantic information of a word. In vocabulary investigation, there have been several questions that need to be addressed. First of all, we need to determine the percentage of lexical items in written or spoken discourse that a learner should know. Even native speakers do not know all the vocabulary of their language. Research suggests that educated native speakers of English know around 20,000 word families (Nation, 2001). A word family includes a number of individual word forms- root form, inflections, and regular derivations (Schmitt, 2008). Regarding how many words a learner should know, recent research suggests that for written discourse $98 \%$ coverage is sufficient (Schmitt, 2008). Nation (2006) analyzed the Wellington Corpus of Spoken English, which included radio, interviews, and friendly conversation between family members and friends, and he calculated that 8000-9000 word families are required to reach the $98 \%$ coverage.

Another concern in the vocabulary investigation is that whether the word in the text is high-frequency word, academic word, technical word or low-frequency word. The high-frequency words include many content words and function words. Academic words include many words that are common in different kinds of academic texts. Technical words are very closely related to the subject area of the text. Low-frequency words include all the words that are not highfrequency words, not academic words not technical words for a special subject (Nation, 2001). In the light of corpus information above, we can note that learners must learn a very large number of lexical items to be successful language users. However, Laufer and Hill (2003) reported that vocabulary sizes of learners are much smaller than the size requirements stated in the research. For example, Japan EFL university learners' vocabulary size is 2000 according to Shillaw (1995). China English majors' vocabulary size is 4000 as stated by Laufer (2001). As the vocabulary size research indicates, principled approaches are needed in promoting vocabulary learning. This highlights the role of the researcher, who will be necessary in providing reliable information about vocabulary and effective methods of learning vocabulary (Schmitt, 2008).

\subsection{Depth of Vocabulary Knowledge}

Another important issue in vocabulary investigation is the quality or the depth of vocabulary knowledge. Knowing a word is not an all-or-nothing phenomenon, but it involves several different aspects of knowing (Nagy \& Scott, 2000). According to Schmitt (2000) vocabulary learning manifests itself in a number of ways. Schmitt $(2000 ; 4)$ notes that "We have all had the experience of being able to recognize and understand a word when we see it in a text, but not being able to use it ourselves. This shows that there are different degrees of knowing a word. Being able to understand a word is known as receptive knowledge and is normally connected with reading and listening. If we are able to produce a word of our own accord when writing or speaking, then that is considered productive knowledge. Moreover, a word's meaning must be learned before that word can be of any use".

According to Nation (2001) knowing a word involves:

a. being able to recognize the word when it is heard

b. being familiar with its written form so that it is recognized when it is met in reading

c. recognizing that it is made up of different parts and being able to relate these parts to its meaning

d. knowing that the word signals a particular meaning

e. knowing what the word means in the particular context in which it has just occurred

f. knowing the concept behind the word which will allow understanding in a variety of contexts

g. knowing that there are related words

$\mathrm{h}$. being able to recognize that the word has been used correctly in the sentence in which it occurs

i. being able to recognize that there are collocations.

As Nation (2001) states there have been different degrees of knowing a word. Therefore, it is not possible to address all levels of word knowledge while measuring how much a learner knows a word. Considering Nation's (2001) word knowledge scale, the present study addresses reading and vocabulary learning and therefore, measures being familiar with its written form and knowing what the word means in the text it has occurred. Moreover, Schatschneider, Harrell and Buck (2007, p. 252) argue that "Vocabulary or word knowledge refers to the ability to understand the meanings of words. To know a word is not an all-or-non proposition. People can have various degrees of understanding of a word, from "never heard it before" to "heard it but can't quite define it" to "can't define it, but can use it in a sentence" to "know it extremely well in all of its nuanced meanings". The estimation of how well one understands a word is often referred to as depth of vocabulary and word knowledge is highly related to reading comprehension. In order to comprehend a text, it would be important to understand most, if not all, of the words in that text".

\subsection{Focus on FonF}

According to Levis (2006) focus on form serves two purposes; to increase learners' awareness and noticing and to improve their output. According to Eliss and Loewen (2002) a distinction has to be drawn between two types of focus on form instruction: planned focus on form is directed at communication tasks to elicit a specific form within meaning, centered language use. It has to be noted that focus on form is pre-determined and planned ahead of instruction. According to above mentioned researchers this type of focus on form is in line with focus on forms in that linguistic forms to be taught are pre-selected.

However it differs from focus on forms in two ways: firstly, 
focus on meaning takes precedence over attention to form. In other words, forms are emphasized to facilitate learning process of communication and meaning. Secondary, learners are not instructed in a way that the focus is merely on a specific feature of language forms. In contrast to focus on forms, according Sheen (2002), focus on form assumes both a similarity and dissimilarity between first and second language acquisition. Similarity is due to the belief that both first and second language acquisition are based on an exposure to comprehensible input arising from natural acquisition.

The dissimilarity, however, comes from the fact that mere natural exposure to language is insufficient to lead SL learners towards linguistic accuracy. Thus, in order to compensate for this insufficiency, some focused attention to linguistic forms is essential. According to VanPatten (2002), in outlining the principles of information processing, attention to form competes with attention to meaning, and learners try to process input for meaning before they process it for form. This suggests that learners need certain activities to be able to attend to form if they can't fulfill this via meaning-focused input.

\subsection{Input Enhancement}

Barcroft (2003) studied input enhancement and second language vocabulary learning with English-speaking L2 learners of Spanish. The participants studied lists of 24 new Spanish words along with their L1 translations in English. In experiment 1, one list of the words had 9 of 24 words enhanced, and the other lists were unenhanced. In experiment 2 , one list of the words had 3 of 24 words enhanced and the other list was unenhanced. Four posttests were administered for immediate and delayed recall. Barcroft concluded that no effect was found for enhancing 9 out of 24 words on learning rates for the enhanced words; no effect was identified for enhancing 9 out of 24 words on learning rates for the unenhanced words and, a positive effect was noted for enhancing 3 out of 24 words on learning rates for the enhanced words based on some but not all dependent measures.

In sum, as Wong (2003, p. 110) has noted, "the contribution of enhancement to SLA is presently not clear". The literature has provided conflicting findings on its efficacy. The findings of previous research suggest that enhancement is either helpful or unhelpful. However, such an understanding is least desirable. From a theoretical standpoint, it neither validates nor invalidates the theory. From a practical standpoint, little can be inferred from the ambiguous findings. Moreover, it appears that there is a need for more data to shed light on the relation between vocabulary learning and input enhancement.

\subsection{Intentional Vocabulary Acquisition and Word-Focused Tasks}

Current definitions of implicit and explicit learning originate in the field of psychology; these definitions generally focus on the absence or presence of consciousness situations. Ellis (1994, p. 1) defines implicit and explicit learning in the following way: "Implicit learning is typically defined as "acquisition of knowledge about the underlying structure of a complex stimulus environment by a process which takes place naturally, simply and without conscious operation", while explicit learning is said to be characterized by "more conscious operation where the individual makes and tests hypotheses in a search for structure" (Ellis 1994, p. 1). As Doughty and Williams (1998) claim "the goal of explicit teaching is to "direct learner attention" whereas the aim of an implicit focus on form is to "attract learner attention" while minimizing any interruption to the communication of meaning. Implicit learning can only be incidental without learners' deliberate decision to commit information to memory". In vocabulary acquisition, a distinction is frequently made which appears to correspond to the implicit/explicit debate: that of incidental vs. intentional vocabulary acquisition. Incidental vocabulary acquisition is generally defined as the "learning of vocabulary as the by-product of any activity not explicitly geared to vocabulary learning" and is contrasted with intentional vocabulary learning, defined as "any activity geared at committing lexical information to memory" (Hulstijn, 2001, p. 271).

\section{Design of the Study}

A proficiency test was used to make vivid that all of the students in the three groups were homogenous. The independent variable is input enhancement and the dependent variables involved bolding, capitalizing, and underlining as prominent factor on vocabulary learning. Learners were distributed into three groups as experimental groups getting different inputs in the texts without any control group. Texts with bolding the target words for first class, the similar texts by underlining the target words for second class and the third one got the same texts by capitalizing the target words. Results were so important, consequently learners tended to apply them because of their comprehensiveness. To sum up, having replied the tests, the elicited data statistically were analyzed and also findings were compared and contrasted and the effects of different input enhancements on vocabulary learning were absolutely presented.

\subsection{Materials}

Data collection was carried out by comparing the findings in three groups. An already settled standard placement test of Oxford University and Cambridge University (2001) was done as a proficiency test in order to certify that all three groups regarding their General English Proficiency were homogeneous. Additionally, four passages by making the target words bold, capitalized, and underlined were presented to the groups due to be conducted during the weeks of treatment to find out that how results of input enhancements are varied. 


\subsection{Procedures}

Conspicuously, at first the participants received a placement test to ensure that they are in the same level. Then, related to the findings of these tests, subjects who got a score between 20 and 40 were selected as homogeneous ones. The participants were put into three experimental groups without any control group. They received four similar texts by employing different input enhancement items; such as bolding, capitalizing, and underlining during the four weeks of treatment. Experimental groups received their treatments and each new words in the passage appeared two or three times. Having read the new words in the passages, some questions were given to the students. Finally, the learners completed the questions and they were collected.

Table 1. Descriptive statistics of groups' normal distribution.

\begin{tabular}{|c|c|c|c|c|c|c|c|c|}
\hline \multicolumn{9}{|c|}{ One-Sample Kolmogorov-Smirnov Test } \\
\hline & \multirow[b]{2}{*}{$\mathrm{N}$} & \multicolumn{2}{|c|}{$\begin{array}{l}\text { Normal } \\
\text { Parameters }^{\mathrm{a}, \mathrm{b}}\end{array}$} & \multicolumn{2}{|c|}{$\begin{array}{l}\text { Most E } \\
\text { Differences }\end{array}$} & Extreme & \multirow{2}{*}{$\begin{array}{l}\text { Kolmo } \\
\text { gorov- } \\
\text { Smirno } \\
\text { v Z }\end{array}$} & \multirow{2}{*}{$\begin{array}{l}\text { Asym } \\
\text { p. } \\
\text { Sig. } \\
\text { (2- } \\
\text { tailed) }\end{array}$} \\
\hline & & Mean & $\begin{array}{l}\text { Std. } \\
\text { Deviati } \\
\text { on }\end{array}$ & $\begin{array}{l}\text { Abso } \\
\text { lute }\end{array}$ & $\begin{array}{l}\text { Posit } \\
\text { ive }\end{array}$ & $\begin{array}{l}\text { Nega } \\
\text { tive }\end{array}$ & & \\
\hline $\begin{array}{l}\text { Placement } \\
\text { test score }\end{array}$ & 60 & 31.63 & 5.845 & .118 & .076 & -.118 & .912 & .377 \\
\hline $\begin{array}{l}\text { Vocabulary } \\
\text { test score } \\
\text { a. Test distri } \\
\text { b. Calculate }\end{array}$ & 60 & $\begin{array}{l}16.00 \\
\text { s Norm } \\
\text { lata. }\end{array}$ & $\begin{array}{l}2.491 \\
\text { al. }\end{array}$ & .122 & .073 & -.122 & .948 & .330 \\
\hline
\end{tabular}

In the end, the true answers of the tasks were elaborated as a class activity. Data were analyzed through applying
Statistical Package for the Social Sciences (SPSS) based on Windows Version 11.0. F-test, and one way ANOVA was applied at the .05 level of significance to answer research question. Descriptive statistics (mean, and standard deviations) were employed.

Table 1illustrates the normal distribution of three groups. So, the researcher applied One-Sample Kolmogorov-Smirnov Test and according to this test level of significance should be above the 0.05 , furthermore, placement test score is 377 and vocabulary test score is 33 and they are more than 0.05 . As a result they are meaningful and have been distributed correctly.

Table 2. ANOVA results of homogeneity in groups.

\begin{tabular}{lllllll}
\hline ANOVA & \multicolumn{7}{c}{ Sum of } \\
& & Squares & Df & $\begin{array}{l}\text { Mean } \\
\text { Square }\end{array}$ & F & Sig. \\
& $\begin{array}{l}\text { Between } \\
\text { Groups }\end{array}$ & 18.633 & 2 & 9.317 & .266 & .767 \\
Placement & Within & 1997.30 & 57 & 35.040 & & \\
test score & Groups & 0 & & & & \\
& Total & 2015.93 & 59 & & & \\
& 3 & & & & & \\
\hline
\end{tabular}

Generally, by comparing the results related to the placement test scores, the researcher used the analysis variance method and if sig $<0.05$, the null hypothesis is rejected. But as it clear in the table, sig. is .737 and it is above 0.05 , so the null hypothesis is not rejected and as a result the placement scores in the three groups do not have any meaningful differences.

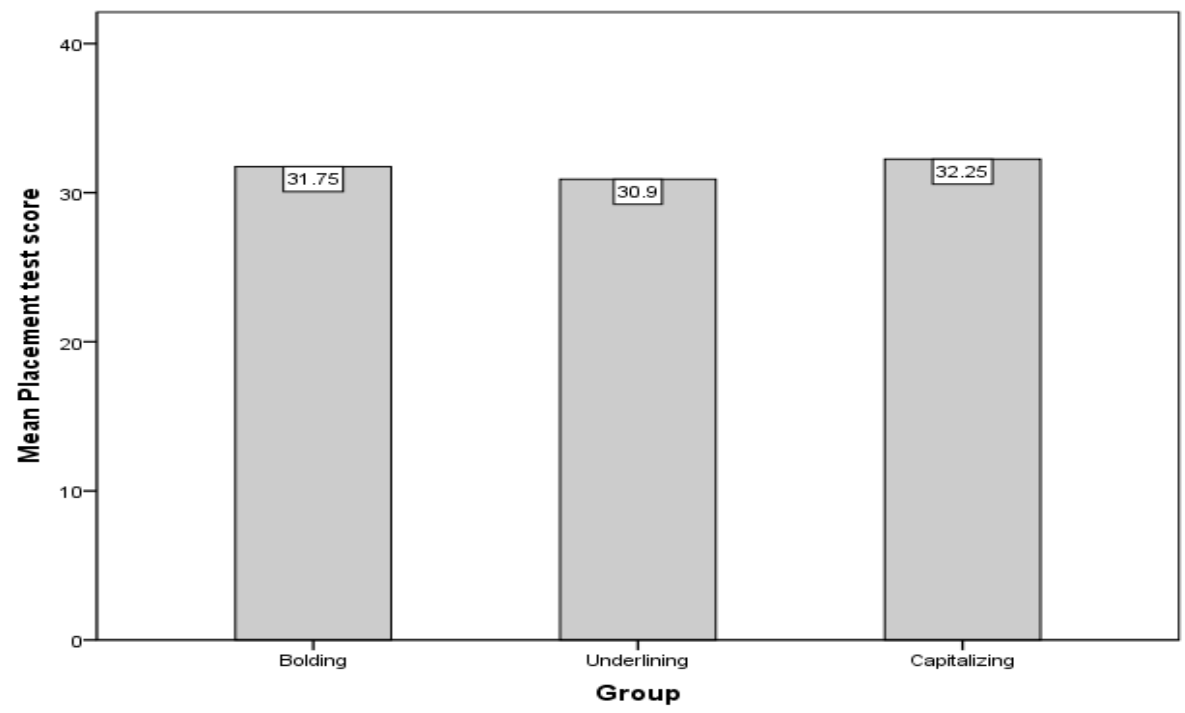

Figure 1. Histogram of learners' homogeneity in three groups.

Table 3. Descriptive statistics of vocabulary in three groups.

\begin{tabular}{|c|c|c|c|c|c|c|c|c|c|}
\hline \multicolumn{10}{|l|}{ Descriptives } \\
\hline & & \multirow{2}{*}{$\mathbf{N}$} & \multirow{2}{*}{ Mean } & \multirow{2}{*}{ Std. Deviation } & \multirow{2}{*}{ Std. Error } & \multicolumn{2}{|c|}{ 95\% Confidence Interval for Mean } & \multirow{2}{*}{ Minimum } & \multirow{2}{*}{ Maximum } \\
\hline & & & & & & Lower Bound & Upper Bound & & \\
\hline \multirow{4}{*}{ Vocabulary test score } & Bolding & 20 & 17.95 & 1.605 & .359 & 17.20 & 18.70 & 15 & 20 \\
\hline & Underlining & 20 & 15.75 & 2.023 & .452 & 14.80 & 16.70 & 12 & 20 \\
\hline & Capitalizing & 20 & 14.30 & 2.342 & .524 & 13.20 & 15.40 & 10 & 19 \\
\hline & Total & 60 & 16.00 & 2.491 & .322 & 15.36 & 16.64 & 10 & 20 \\
\hline
\end{tabular}




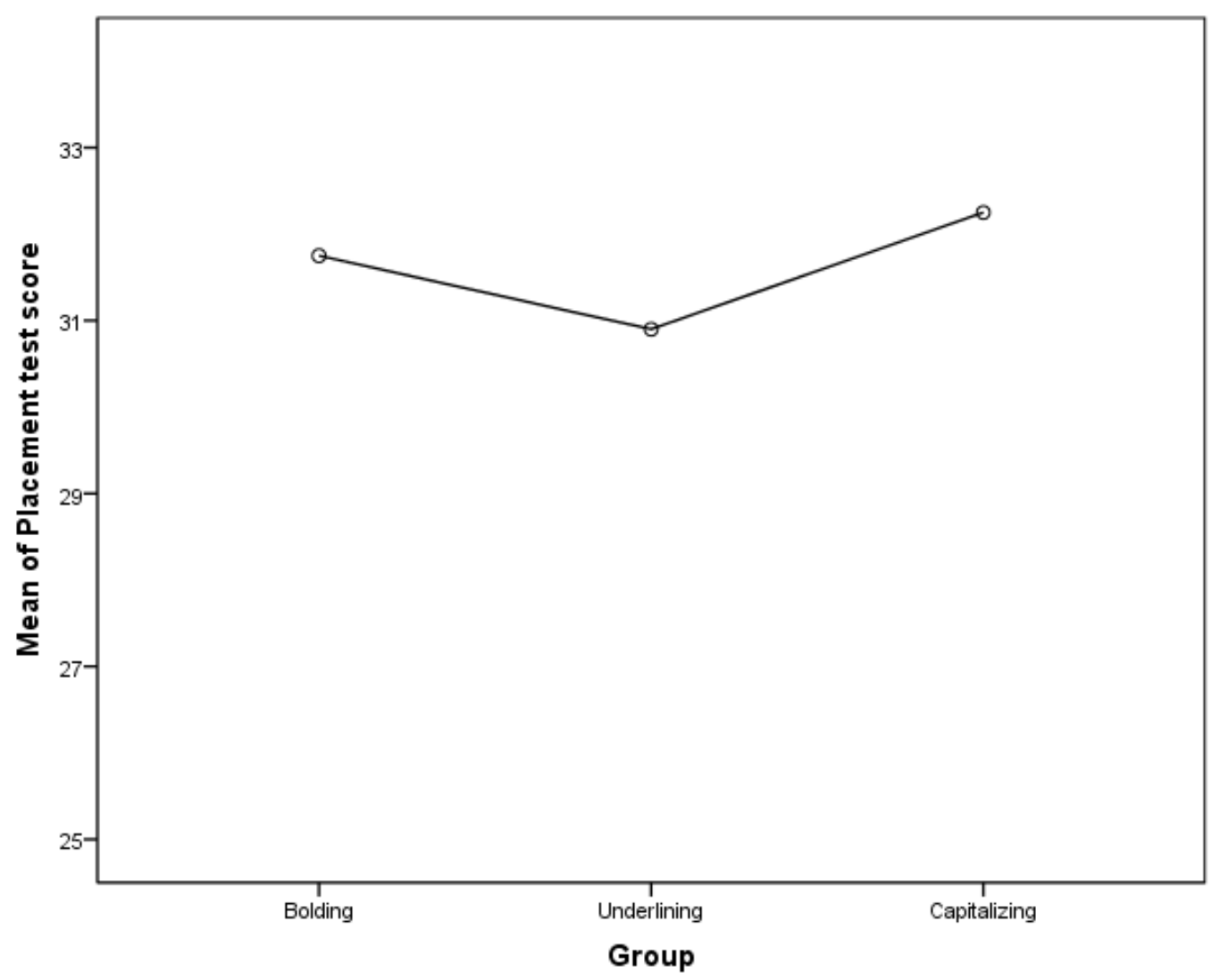

Figure 2. Means plot of homogeneity in different groups.

Table 4. ANOVA results of vocabulary in three groups.

\begin{tabular}{|c|c|c|c|c|c|c|}
\hline \multicolumn{7}{|l|}{ ANOVA } \\
\hline & & $\begin{array}{l}\text { Sum of } \\
\text { Squares }\end{array}$ & df & $\begin{array}{l}\text { Mean } \\
\text { Square }\end{array}$ & $\mathbf{F}$ & Sig. \\
\hline \multirow{3}{*}{$\begin{array}{l}\text { Vocabulary } \\
\text { test score }\end{array}$} & $\begin{array}{l}\text { Between } \\
\text { Groups }\end{array}$ & 135.100 & 2 & 67.550 & \multirow[t]{3}{*}{$\begin{array}{l}16.6 \\
75\end{array}$} & \multirow[t]{3}{*}{.000} \\
\hline & $\begin{array}{l}\text { Within } \\
\text { Groups }\end{array}$ & 230.900 & 57 & 4.051 & & \\
\hline & Total & 366.000 & 59 & & & \\
\hline
\end{tabular}

The mean difference is significant at the .05 level.

Dependent Variable: vocabulary learning

Table 5 shows that there are significant differences among the groups. The results showed that, the bolding group acquired statistically significant more than others and capitalizing group acquired the lowest mark among the groups.

The results of the descriptive statistics for vocabulary in all the three groups during the nine sessions of the study are presented in the Table 3.Table 3 categorizes mean and standard deviation of bolding, underlining, and capitalizing groups' in vocabulary tests. Learners, who received different inputs, had varied mean and standard deviations. So, as it is shown, bolding group's mean is achieved by 17.95 and standard deviation by 1.60 , underlining group's mean is 15.75 with standard deviation of 2.02, and mean of 14.30 and standard deviation of 2.34 are respectively devoted to capitalizing group. Consequently, bolding group did better than other groups and it shows its' significant and value effects on participants while answering the vocabulary questions.

Table 5. Multiple comparisons of vocabulary test results in bolding, underlining, and capitalizing groups.

\begin{tabular}{|c|c|c|c|c|c|c|c|c|}
\hline \multicolumn{9}{|l|}{ Multiple Comparisons } \\
\hline \multirow{2}{*}{ Dependent Variable } & & \multirow{2}{*}{ (I) Group } & \multirow{2}{*}{ (J) Group } & \multirow{2}{*}{ Mean Difference (I-J) } & \multirow{2}{*}{ Std. Error } & \multirow{2}{*}{ Sig. } & \multicolumn{2}{|c|}{ 95\% Confidence Interval } \\
\hline & & & & & & & Lower Bound & Upper Bound \\
\hline \multirow{6}{*}{ Vocabulary test score } & \multirow{6}{*}{ LSD } & \multirow{2}{*}{ Bolding } & Underlining & $2.200^{*}$ & .636 & .001 & .93 & 3.47 \\
\hline & & & Capitalizing & $3.650^{*}$ & .636 & .000 & 2.38 & 4.92 \\
\hline & & \multirow{2}{*}{ Underlining } & Bolding & $-2.200^{*}$ & .636 & .001 & -3.47 & -.93 \\
\hline & & & Capitalizing & $1.450^{*}$ & .636 & .026 & .18 & 2.72 \\
\hline & & \multirow{2}{*}{ Capitalizing } & Bolding & $-3.650^{*}$ & .636 & .000 & -4.92 & -2.38 \\
\hline & & & Underlining & $-1.450^{*}$ & .636 & .026 & -2.72 & -.18 \\
\hline
\end{tabular}

Obviously, in the present study, the significant level is $\mathrm{p}<0.05$ and according to table 4 and based on the ANOVA 
series tests and Levin test which is used in this stage, it is observed that $\operatorname{sig}=.000$ and $\mathrm{F}=16.675$, so it could be inferred that noticeable differences exist among the vocabulary test scores in different groups of learners. Therefore, the difference between groups is statistically significant and it means that the groups with different inputs, performed differently after receiving distinct types of treatments. Consequently, null hypothesis which states that Bolding, Capitalizing, Underlining some especial words do not have different effects on L2 learners' vocabulary knowledge enhancement is rejected and the directional hypotheses is confirmed.

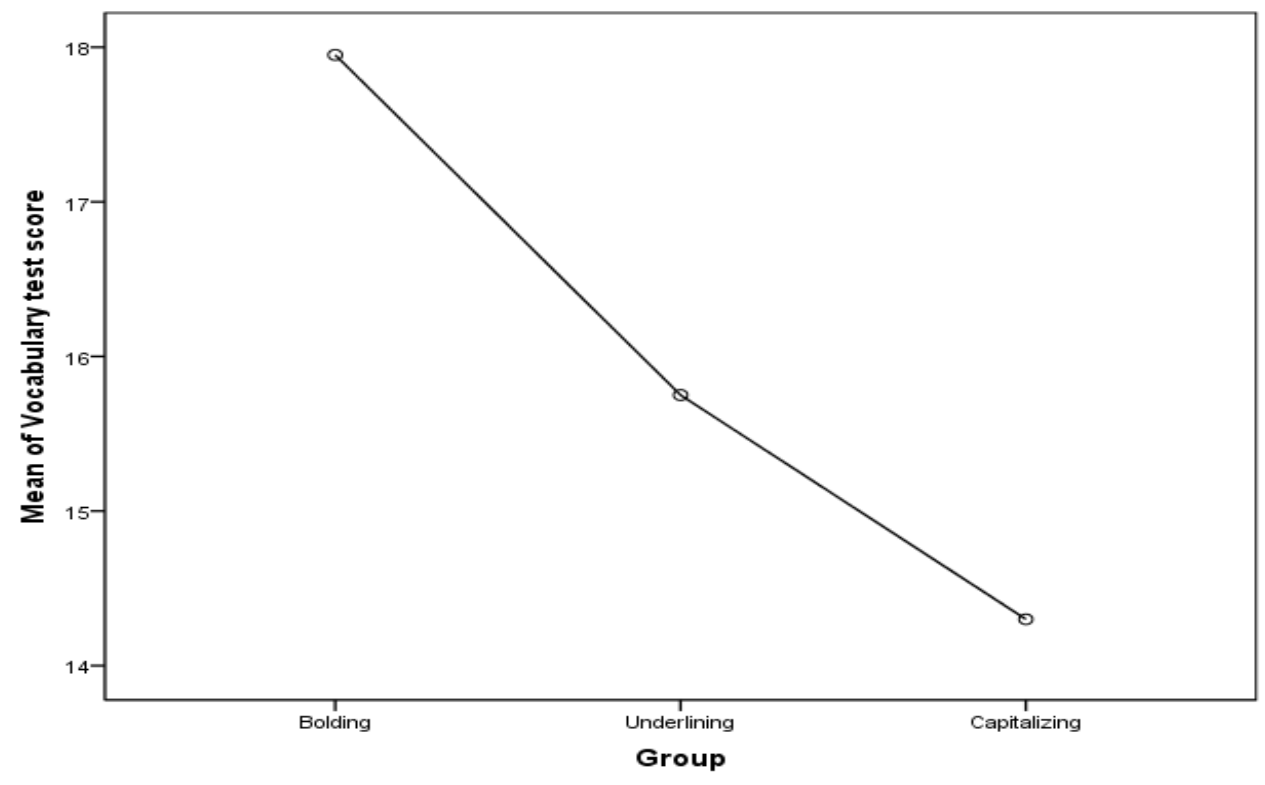

Figure 3. Means plot of bolding, underlining and capitalizing groups.

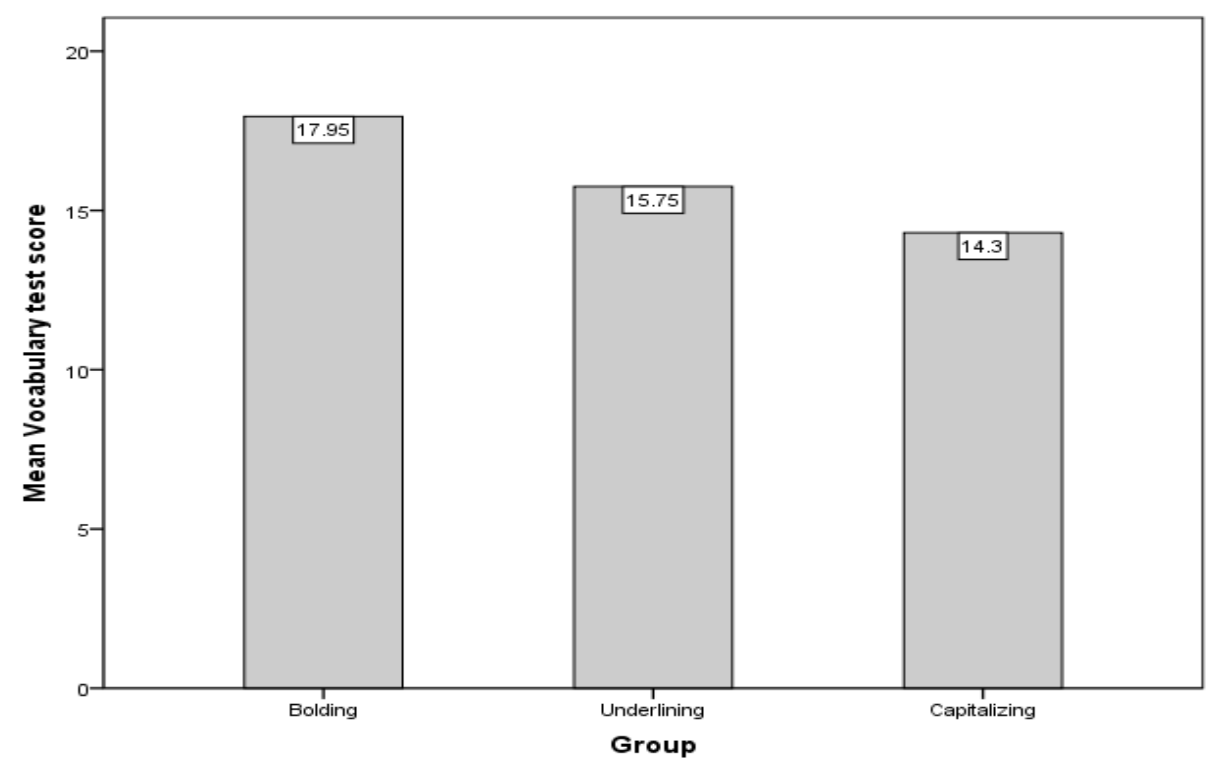

Figure 4. Histogram of learners' vocabulary test results in three groups.

These descriptive statistics results described the most and the least frequently used strategies, respectively as bolding and capitalizing inputs.

\section{Conclusion and Discussion}

Mainly, the findings of this study showed that bolding group outperformed the underlined and capitalized groups. The participants were 60 intermediate English learners in ILI
Institute in Tabriz. The materials were four texts including some vocabulary questions. In a study by Shook (1994), 125 first and second year learners of Spanish participated in the study. The target forms were Spanish present perfect tense and relative pronouns written in larger font and bold form. Three groups were selected. The first group received text enhancement only. The second group received text enhancement with direction to pay attention to form and the third group were control group with no enhancement and no 
directions to pay attention to form. They were tested through a production test of relative pronouns, a production test of present perfect, a recognition test of relative pronouns, and a recognition test of present perfect. The results showed that the two text enhancement groups performed significantly better than the control group on all tasks, but no significant difference was found between those explicitly asked to attend to form and those without such directions. So, the findings of our research are in line and related with the findings of Shook's (1994) research and showed that input enhancement items were effective in developing learners' vocabulary knowledge and this input has a positive impact on students' vocabulary progression. And also some studies showed negative effect of enhanced written input on L2 target features learning. In a study by Overstreet (1998), 50 native English speaking third semester university learners of Spanish took part in the study. The target form was imperfect tense in Spanish. They were underlined, bold and enlarged. Four groups were selected. The first group received familiar content and textual enhancement, second group received familiar content but no textual enhancement, the third group received unfamiliar content with textual enhancement and the fourth group received textual content with no textual enhancement. Students were tested through a true/false comprehension quiz in participants L2, a narration task of form and a circle the verb task. The results showed no positive effect for either content familiarity or textual enhancement on participants' intake of target form or comprehension, and they showed a negative effect for textual enhancement on meaning comprehension. So these findings clash with the findings of our research, because our research showed that highlighted (bold) group outperformed other groups. The result was satisfactory and it can be concluded that input enhancement is a useful and effective technique to draw learners' attention to target words and elevate "noticing" which the gate way for vocabulary learning. As mentioned earlier, the researcher tried to find the different categories of input enhancement as an effective way of promoting learners' vocabulary knowledge especially bolding in particular, was the most obvious one compared to the others.

\section{Acknowledgements}

I could not have completed this essay, or graduate university, without the encouragement, guidance, and care from a core group of people. First and foremost, my beloved parents who changed their world and friends who have provided tremendous support throughout my post graduate studies, finally my partner of life and my lovely daughter. Words do little to convey how thankful I am to all of them. My great professors have consistently warmed by heart, and taught me to appreciate the little things. I am deeply indebted to my great professor Dr. Farahman Farrokhi for giving me the positive energy and hope to study and do the research. He is the best supervisor a student could ever ask for. Finally, I'd like to thank Dr. Mohammad Zohrabi, Dr. Naser Ghafoori, for their encouragements and continued assistances and giving me the opportunity to become aware of my infinite ignorance.

\section{References}

[1] Catherina Doughty, Jessica Williams (1998) Focus on form in classroom second language acquisition. Cambridge University Press.

[2] Clarke, D., \& Nation, I.S.P. (1980).Guessing the meanings of words from context: Strategy and techniques. System, 8, 211220 .

[3] Coady, J., \& Huckin, T. (1999). Incidental vocabulary acquisition in a second language: A review. Studies in second language acquisition, 21 (2), 181-192.

[4] Dekeyser, R.M. (2000). The robustness of critical period effects in second language acquisition. Studies in Second Language Acquisition, 22, 499-533.

[5] Doughty, C., \& Williams, J. (1998). Focus on form in classroom second language acquisition. Cambridge: CUP.

[6] Ellis, R., Baştürkmen, H., \& Loewen, S. (2001). Preemptive focus on form in the ESL classroom. TESOL Quarterly, 35(3), 407-432.

[7] Ellis, N.C., Beaton, A. (1993).Psycholinguistic determinants of foreign language vocabulary learning. Language Learning, 43(4), 559-617.

[8] Gass, S. (1988). Integrating research areas: A framework for second language studies. Applied Linguistics, 9, 198-217.127

[9] Hulstijn, J.H., \& Laufer, B. (2001).Some empirical evidence for the involvement load hypothesis in vocabulary acquisition. Language Learning, 51(3), 539-558.

[10] Kim, Y. (2008). The Role of Task-Induced Involvement and Learner Proficiency in L2 Vocabulary Acquisition. Language Learning, 58(2), 285-325.

[11] Krashen, S.D. (1989). We acquire vocabulary and spelling by reading: Additional evidence for the input hypothesis. Modern Language Journal, 73, 440-464.

[12] Laufer, B., \& Girsai, N. (2008). Form-focused instruction in second language vocabulary learning: A case for contrastive analysis and translation. Applied Linguistics, 29(4), 694-716.

[13] Lee, S.H. (2007). Effects of textual enhancement and topic familiarity on Korean EFL students reading comprehension and learning of passive form. Language Learning, 57(1), 87118 .

[14] Leow, R.P. (2001). Attention, awareness and foreign language behavior. Language Learning, 51, 113-155.

[15] Long \& Robinson, (1998). The handbook of second language acquisition. John Wiley \& Sons.

[16] Nation, I.S.P. (2006). How large a vocabulary is needed for reading and listening? Canadian Modern Language Review, 63(1), 59-82.

[17] Presley, M., Levin, J.R., \& Delaney, J.D. (1982).The mnemonic keyword method. Review of Educational Research, $52,61-91$. 
[18] Richard Schmit, (1990, 1993) Attention and awareness in foreign language learning. Natl Foreign Lg Resource Ctr.

[19] Robinson, P. (2002). Effects of individual differences in intelligence, aptitude and working memory on adult incidental SLA. In P. Robinson (Ed.) Individual differences and instructed language learning, 211-266. Philadelphia: John Benjamins.

[20] Rott, S. (1999).The effect of exposure frequency on intermediate language learners' incidental vocabulary acquisition and retention through reading. Studies in Second Language Acquisition, 21(4), 589-619.

[21] Schatschneider, C., Harrell, E.R., \& Buck, J. (2007). An individual differences approach to the study of reading comprehension. In R.K. Wagner, A.E. Muse, \& K.R. Tannenbaum (Eds.) Vocabulary acquisition: Implications for reading comprehension, 249-275. New York: Guilford Press.
[22] Schmidt, R. (1994). Implicit learning and the cognitive unconscious: Of artificial grammars and SLA. In N. Ellis (Ed.).Implicit and explicit learning of languages, 165-209. London: Academic Press.

[23] Schmidt, R. (2000). Attention. In P. Robinson(ed.). Cognition and second language instruction. Cambridge: CUP.136.

[24] Schmitt, N. (2000). Vocabulary in Language Teaching, Cambridge: CUP.

[25] Schmitt, N. (2008). Review article: Instructed second language vocabulary learning. Language Teaching Research, 12(3), 329-363.

[26] Sharwood-Smith, M. (1993). Input enhancement in instructed second language acquisition: Theoretical bases. Studies in Second language acquisition, 15, 165-179.

[27] Sheen, Y. (2002) Yellow umbrella. Kane/Miller Book Pub. 